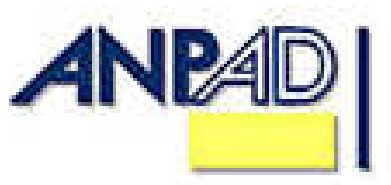

Disponível em http://www.anpad.org.br/rac

RAC, Curitiba, v. 13, n. 2, art. 5, p. 247-271, Abr./Jun. 2009

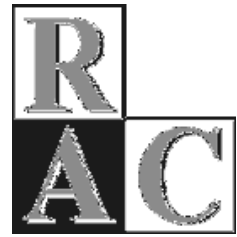

\title{
Análise Empírica do Senso de Controle: Buscando Entender o Excesso de Confiança
}

\section{Sense of Control Empirical Analysis: Understanding Overconfidence}

Wesley Mendes-da-Silva *

* Endereço: Wesley Mendes-da-Silva

Av. Prof. Luciano Gualberto, 908, Cidade Universitária, São Paulo/SP, 05508-900. E-mail: mr.mendesdasilva@gmail.com

Copyright (C) 2009 RAC. Todos os direitos, inclusive de tradução, são reservados. É permitido citar parte de artigos sem autorização prévia desde que seja identificada a fonte. 


\title{
RESUMO
}

No emergente campo das finanças comportamentais, em cujo contexto são abordados detalhes do comportamento humano, relativos à tomada de decisões financeiras, estes detalhes são considerados implicações da psicologia cognitiva e da sociologia. Desse modo, a ainda pequena, porém crescente, produção científica acerca dessa temática no âmbito nacional, tem considerado essencialmente as conseqüências dos vieses cognitivos dos agentes, que podem comprometer a validade de julgamentos realizados. Alguns dos vieses cognitivos, como o excesso de confiança e a procrastinação, considerados na literatura, sofrem influência do senso de controle que cada indivíduo possui. Desse modo, o objetivo deste artigo é verificar associações entre idade e senso de controle, analisando os efeitos mediadores de outras características pessoais sobre essa associação. O estudo é conduzido a partir de dados coletados no primeiro trimestre de 2006, em 421 indivíduos residentes no Brasil. Os principais resultados sugerem uma associação quadrática significativa, do tipo $\mathbf{U}$ invertido, entre idade e senso de controle, estando essa relação sob a influência da educação e da percepção de saúde geral do indivíduo. Assim, parece que as pessoas têm a evolução de seu senso de controle ao longo da vida mediada pela sua educação, como também por sua saúde.

Palavras-chave: senso de controle; excesso de confiança; erros cognitivos; finanças comportamentais.

\begin{abstract}
In the emerging field of behavioral finance, where details of human behavior concerning financial decision making are broached, implications of cognitive psychology and sociology are considered. In this way, scientific production, still small but making steady headway, of this thematic in the national scope has essentially laid more focus on the consequences of the cognitive biases of agents, which can reduce the validity of judgments which have been made. Some of the cognitive biases considered in literature, such as overconfidence and procrastination, are influenced by the sense of control that each person possesses. In this way, this article aims to verify associations between age and sense of control, analyzing the mediating effect of other personal characteristics on this association. The study stems from data collected during the first trimester of 2006, from 421 people living in Brazil. The main results suggest a significant quadratic association, like an inverted $\mathbf{U}$ curve, between age and sense of control, with this relationship being influenced by the level of education and the perceived general health conditions of each individual. It would seem, therefore, that the evolution of people's sense of control during their lifetimes is influenced by their education and global health.
\end{abstract}

Key words: sense of control; overconfidence; cognitive biases; behavioral finance. 


\section{INTRODUÇÃO}

Segundo os pressupostos da Moderna Teoria de Finanças [MTF], os agentes devem considerar todas as informações disponíveis a respeito de uma decisão a ser tomada, atribuindo a cada uma delas pesos diferenciados, tendo em vista suas validade e relevância. Mas, nos diversos grupos de profissionais, existem tendências a superestimar a validade de seus próprios julgamentos, o que é conhecido na literatura como excesso de confiança, decorrente do nível de senso de controle que um indivíduo possui. Assim, a racionalidade das decisões tomadas pelos investidos tem sido contestada pelo emergente campo das finanças comportamentais. Nesse contexto, os impactos de diversos aspectos do comportamento humano no mercado têm sido estudados. Porém, especialmente no Brasil, essa área de conhecimento ainda é carente de produção científica acerca do entendimento de como esses aspectos comportamentais se apresentam nos indivíduos, segundo suas características pessoais, tais como idade, educação, status marital, e status de ocupação.

Freqüentemente, a aquisição de ativos de longo prazo é fonte de stress para as pessoas. Desse modo, adquirir o primeiro apartamento, por exemplo, torna-se assunto em que as pessoas costumam não pensar, especialmente pelo incômodo que provoca em suas mentes, provavelmente também por perfeccionismo ou medo de errar. A conseqüência desse sentimento é a postergação ilógica do início das ações e decisões pessoais que, oportunamente implementadas, poderiam contribuir para o atingimento da meta principal, a compra do primeiro apartamento, por exemplo. Em ocasiões desse gênero, as pessoas têm seu senso de controle da situação significativamente diminuído, ou melhor, a situação relativa a um aspecto essencial para o próprio bem-estar do indivíduo vai paulatinamente recaindo em indesejável senso de descontrole.

A postergação ilógica, intrínseca ao comportamento das pessoas, é denominada como procrastinação, usualmente vista como fenômeno negativo, pressupondo-se algumas características de irracionalidade. Também consiste no tratamento de tarefas necessárias às vidas das pessoas, que existem em grande quantidade e que, muitas vezes, são deixadas para épocas futuras, quando deveriam ser iniciadas imediatamente. Algumas causas da procrastinação são apontadas na literatura de psicologia: depressão, ansiedade extrema, déficit de atenção, e desorganização; todas elas são contributivas para a formação do senso de controle que as pessoas têm a respeito de suas próprias vidas.

A partir da idéia de que as pessoas perseguem a maximização de seu bem-estar, o senso de controle constitui tema relevante para melhor entender como as pessoas podem decidir sobre temas que afetam ou afetarão a manutenção de seu estilo de vida, destacadamente itens relacionados a investimentos pessoais, como é o caso da constituição de aposentadoria. Ademais, na ausência do senso de controle, as pessoas tendem a sentir-se inseguras, possibilitando o desencadeamento de efeitos sobre seu desempenho, no exercício de papéis na sociedade, na convivência familiar, ou mesmo no desenvolvimento de suas atividades profissionais. Essas noções de como as pessoas tomam decisões têm motivado o rápido crescimento do campo das finanças comportamentais ao redor do mundo. Por outro lado, no âmbito nacional, a questão ainda se encontra pouco explorada.

Desde meados de 2003, o mercado de capitais brasileiro tem experimentado um vertiginoso crescimento do volume de negócios, atingindo nível superior a $\mathrm{R} \$ 91 \mathrm{mi}$, em um dia do primeiro bimestre de 2007, ocasionando uma pontuação record do Ibovespa ao redor de 45.474 pontos. Mas, possivelmente, uma parcela desses negócios pode ser atribuída a efeitos de erros cognitivos dos agentes. Algumas empresas têm alcançado níveis de valorização de mercado bastante elevados, notadamente quando observados os índices preço-lucro, os quais são medidas de quão caro está o mercado, em relação a uma medida objetiva da capacidade de as firmas alcançarem lucros futuros. A partir desse raciocínio, algumas empresas, sobretudo as que abriram seu capital mais recentemente, parecem estar passando por momentos de supervalorização. Por quais motivos, então, o mercado nacional tem atingido níveis tão elevados nos últimos tempos? Que fatores estariam contribuindo para 
que houvesse tal valorização? Que representa isso para uma concepção geral do mercado nos primeiros anos deste século?

Existem fatores para manter o mercado em alta, ou para que alcance volumes de negociação maiores ainda? Ou o mercado estaria nesse nível de valorização pela influência de variáveis comportamentais dos investidores, tal como a expectativa de altas taxas de retorno, a qual dificulta a percepção da situação real? Na opinião de Shiller (2000), a resposta a essas questões é fundamental para os interesses da sociedade, sejam eles de natureza pública ou privada; a maneira como é avaliado o mercado de ações, agora e no futuro, influencia importantes decisões da política social e econômica, cujos impactos se refletem não apenas nos investidores, mas também na sociedade de maneira geral. Desse modo, assume-se que tanto a superavaliação, quanto a estimação deficitária do valor de um ativo, não raro decorrentes de erros cognitivos, constituem motivo de preocupação.

Essas questões têm sido tratadas essencialmente sob o foco da MTF, a qual assume que as preferências individuais são racionais. No entanto, alguns pesquisadores defendem que, para que a teoria das finanças se torne mais aplicável, os aspectos mais confusos da realidade do mercado hão de ser investigados. Segundo resultados obtidos em pesquisas recentes, julgamentos equivocados quanto a acontecimentos futuros são afetados pelas expectativas de cada agente, por ocasião de seu julgamento. A ainda pequena, porém crescente, produção científica acerca dessa temática, no âmbito nacional, tem considerado essencialmente as consequiências dos vieses cognitivos dos agentes, que podem comprometer a validade de julgamentos. No entanto as origens dos vieses cognitivos não têm recebido igual atenção.

Diante disso, o objetivo deste artigo é verificar associações entre idade e senso de controle, analisando os efeitos mediadores de outras características pessoais e sociais. Os principais resultados deste estudo apontam uma relação quadrática, do tipo $\mathbf{U}$ invertido, entre a idade dos indivíduos e o senso de controle, isto é, tanto as pessoas mais jovens, quanto as que se encontram em faixas etárias mais avançadas, tendem a apresentar menores níveis de senso de controle, quando comparadas àqueles indivíduos com idade próxima de um adulto jovem. Outro resultado encontrado foi o efeito mediador da associação entre a idade e o senso de controle exercido pela educação e pela percepção de saúde relatada pelos indivíduos.

Além dessa introdução, este artigo é composto de mais quatro seções. Na segunda seção apresentamse as bases teóricas do estudo, onde se abordam essencialmente os seguintes elementos: origem das finanças comportamentais; aspectos da microeconomia relativos à racionalidade dos agentes; definição conceitual do senso de controle; associação entre idade e senso de controle, bem como impactos de variáveis demográficas e sociais para a relação entre idade e senso de controle. A terceira seção apresenta os procedimentos metodológicos adotados no trabalho. Em seguida, na quarta seção, são apresentados e discutidos os resultados alcançados. Por fim, na quinta seção, comparecem as considerações finais do estudo.

\section{BASES TEÓRICAS DO ESTUDO}

Pesquisas de psicologia cognitiva, cujos estudos pioneiros são atribuídos a Tversky e Kahneman (1971, 1974) e a Kahneman e Tversky $(1972,1979)$, têm buscado examinar a validade da assunção da racionalidade dos agentes, segundo a MTF, bem como o melhor entendimento do comportamento desses últimos, mediante erros cognitivos. Esses trabalhos introduzem a possibilidade de que, nas suas tomadas de decisão, agentes financeiros empreguem processos heurísticos, podendo incorrer sistematicamente em vieses cognitivos que, se combinados, vão de encontro aos pressupostos da MTF.

Tais aspectos são discutidos também por Thaler (1991, 1999, 2000), que se refere a essas circunstâncias como quasi-racionalidade do agente: "trying hard but subject to systematic error" (Thaler, 2000, p. 136). Por sua vez, Buchanan e Huczynski (2004, p. 762) definem viés cognitivo 
como 'predisposição a prejulgamentos ou distorções sistemáticas'. A partir dessas idéias, nas últimas duas décadas, tem aumentado o interesse não somente da comunidade acadêmica, mas também do ambiente empresarial, pelas associações entre psicologia dos julgamentos que as pessoas realizam, e o processo de tomada de decisão. Indicações desse interesse já se notavam nos trabalhos de Zimbarbo e Leippe (1991); Fiske e Taylor (1991); e de Plous (1993).

A literatura de finanças comportamentais aborda alguns dos vieses cognitivos. Porém é essencialmente na insuficiência de investigações não somente das consequiências, mas também das origens desses vieses, que essa emergente área de conhecimento tem sido criticada. Bazerman (2004) é um dos autores que se têm dedicado ao entendimento e conceituação dos processos heurísticos associados a erros de julgamento.

a) Representatividade. Inicialmente examinada por Tversky e Kahneman (1974), indivíduos que utilizam essa heurística tendem a fazer julgamentos baseados em esteriótipos previamente formados. Esse viés cognitivo induz um comportamento de ignorar o papel do tamanho de uma amostra, por exemplo; ou melhor, na intuição de algumas pessoas, o tamanho da amostra não é fator relevante, apesar de constituir matéria essencial em estatística.

b) Ancoragem ou ajustamento. As pessoas tendem a fazer julgamentos a partir de um valor inicial, que será ajustado para a obtenção de uma resposta final. Assim, para Slovic e Lichtenstein (1971), o ajustamento realizado freqüientemente não oferece condições para considerar racional a escolha do agente. Desse modo, decisões tomadas em contextos similares podem apresentar-se diferentes, em decorrência de valores de referência distintos.

c) Disponibilidade. Os eventos mais freqüentes são mais facilmente lembrados. Adicionalmente, os eventos mais prováveis são mais lembrados que os improváveis. Esta heurística, segundo Bazerman (2002), pode induzir o agente a erros sistemáticos na tomada de decisões gerenciais.

d) Teoria do Prospecto. Foi proposta por Tversky e Kahneman (1974), que defendem que cada decisão deve ser avaliada segundo seu contexto geral, contrapondo a teoria da utilidade esperada. Esses autores argumentam ainda que ganhos e perdas são avaliados relativamente a um ponto neutro de referência, e que a dor associada à perda de um valor $\$ \mathrm{X}$ é maior que o prazer associado ao ganho dos mesmos $\$ X$, existindo uma tendência de superavaliar eventos de pequena probabilidade e subavaliar eventos de média e grande probabilidade.

Os erros de cognição têm sido considerados em pesquisas de diversos campos de conhecimento, como análise de decisão, estratégia empresarial e finanças (Schwenk, 1984). Entre esses, alguns estão associados ao senso de controle, ao sentimento de controle sobre as situações. Por exemplo, excesso de otimismo, ilusão de controle, e excesso de confiança, que consistem essencialmente na superautoavaliação sistemática de capacidade, por parte de um agente (Fisher \& Statman, 2000). Na área de negócios, gerentes tendem a ser excessivamente confiantes na aquisição ou no apreçamento de ativos, por exemplo. Profissionais de outras áreas do conhecimento, como medicina, direito, e engenharia, também têm demonstrado excesso de confiança em suas decisões. A partir dessas idéias, para Lichtenstein, Fischhoff e Phillips (1982), o senso de controle, aliado a fatores demográficos e sociais, desempenha papel preponderante no entendimento de erros cognitivos a ele associados.

\section{A Decisão de Investir}

Entender por que, e em que as pessoas investem, são as questões centrais para economistas, e formuladores de políticas públicas. Na ótica da teoria neoclássica, os ganhos com investimentos são resultado da decisão das pessoas mediante o trade off consumo atual versus futuro. O modelo do ciclo de vida, discutido por Modigliani e Brumberg (1954) assume que os indivíduos são racionais no momento de definir seu consumo e sua necessidade de investimento ao longo de suas vidas.

$\mathrm{Na}$ abordagem baseada na preferência, os objetivos da decisão são expressos em relações de preferência, as quais Mas-Colell, Whiston e Green (1995, p. 6) denotam por $\succ$. Tecnicamente, $\succ$ é 
uma relação binária no conjunto de alternativas $X$, sugerindo a comparação de pares de alternativas $x$, $y \in X$. Lê-se $x \succ y$ como " $x$ é tão bom quanto $y$ ". A partir de $\succ$, pode-se derivar duas importantes relações em $X$ : (i) A relação de preferência estrita, definida por $x \succ y \Leftrightarrow x \succ y$, mas não $y \succ x$; e é lida " $x$ é preferida a $y$ ". (ii) A relação de indiferença, , definida por $x \sim y \Leftrightarrow x \succ y$ e $y \succ x$; e é lida " $x$ é indiferente a $y$ ". Na Teoria Microeconômica assume-se que as preferências individuais são racionais. Por sua vez, a hipótese de racionalidade é sustentada por duas premissas básicas sobre as relações de preferência $\succ$ : completeza e transitividade. Então, a relação de preferência $\succ$ é racional quando satisfaz a essas duas propriedades: completeza: $\forall x, y \in X \Rightarrow x \succ y$ ou $y \succ x$ (ou ambos);

transitividade: $\forall x, y, z \in X$, se $x \succ y$ e $y \succ z$, então $x \succ z$.

A assunção de que $\succ$ é completa diz que um indivíduo possui preferência bem definida entre as alternativas possíveis numa escolha, ou melhor, que o consumidor é capaz de escolher entre as alternativas apresentadas. Já a transitividade implica que é impossível que um tomador de decisão possua uma seqüência de escolhas em que as preferências apareçam em ciclo. Por exemplo, se o consumidor assume que $x$ é pelo menos tão boa quanto $y$, e que $y$ é pelo menos tão boa quanto $z$, então ele acha que $x$ é pelo menos tão boa quanto $z$. Por sua vez, não está claro se a transitividade de preferências é necessariamente uma propriedade obrigatória das preferências. Nesse contexto, o conceito da racionalidade do tomador de decisão, apresentado na Teoria da Utilidade, seria refutável.

Segundo Modigliani e Brumber (1954), durante os primeiros anos da vida adulta, trabalhadores tendem a comportar-se como gastadores, assumindo endividamento na medida em que tomam emprestados valores futuros, com o objetivo principal de aumentar a sua capacidade de consumo atual. Já os indivíduos de meia idade tornam-se investidores e compradores de ativos financeiros, e entram na fase de acumulação, durante a qual eles estocam ativos para a fase de retirada (desacumulação de riqueza) no final de sua vida. A partir da assunção de que os ganhos advindos do trabalho freqüentemente tendem a diminuir, ou mesmo desaparecer, as pessoas desacumulam, ou desperdiçam recursos financeiros, no consumo realizado em faixas etárias mais avançadas. Assim, segundo os princípios da teoria do ciclo da vida, as pessoas desenvolverão logicamente ativos suficientes para protegê-los nos momentos de crise inesperada (maior necessidade), tendo em vista a manutenção de seu padrão de vida.

Para Aizcorbe, Kennickell e Moore (2003), os valores totais investidos pelas pessoas tendem a aumentar com a idade, estando positivamente associados ao seu nível de instrução e à sua saúde geral. Desse modo, cidadãos mais jovens geralmente têm mais dívidas que ativos, enquanto adultos jovens iniciam investimentos, no mesmo tempo em que acumulam ativos. Finalmente, na fase final da vida, os indivíduos tendem a consumir porções de seus ativos financeiros. De maneira alternativa, parece que alguns comportamentos podem não estar alinhados com a teoria do ciclo de vida. Considerando inicialmente uma questão fundamental: quão bem os cidadãos estão calculando o nível apropriado de investimentos, para assegurar a manutenção de seu padrão e estilo de vida? Ora, se a teoria do ciclo de vida é verdadeira, os indivíduos teriam que demonstrar excelente capacidade de estimar suas necessidades de recursos para a aposentadoria e a análise dos investimentos atuais seria uma indicação de sua competência para assumir tal tarefa.

Mas o bem-estar pessoal, nas fases de maior necessidade, requer estimativas acuradas, contemplando incertezas do mundo futuro com relação a aspectos como: ganhos ao longo da vida; retorno proporcionado pelos ativos financeiros; taxas de juros; status social; saúde da família; e longevidade. Assim, para resolver esse problema, a mente humana trabalharia como máquina de calcular; necessitaria a capacidade de resolver problemas relativos ao dinheiro em muitas décadas, com significativa incerteza, como fluxo de caixa estocástico ao longo do tempo.

A decisão de investir, envolvendo as questões que influenciam os resultados desse investimento, está submetida a diversos problemas cognitivos. Um indício dessa ótica pode ser verificado nos dados disponibilizados anualmente pelo Employee Benefit Research Institute [EBRI], nos Estados Unidos; tais dados têm atestado que freqüentemente os indivíduos possuem baixa capacidade para estimar a sua necessidade de investimento. Desse modo, resultados consistentes de várias pesquisas realizadas 
apontam uma parcela de aproximadamente $40 \%$ dos trabalhadores com alguma idéia de quanto deveriam poupar; e somente $20 \%$ sentiam-se seguros quanto ao seu próprio futuro, tendo em vista seu senso de controle baseado nos investimentos realizados (EBRI, 2003). Isto contraria a premissa da racionalidade no planejamento dos investidores, abordada no modelo do ciclo de vida.

O campo das finanças comportamentais, no mesmo tempo em que vem ganhando espaço na academia, também tem sido alvo de críticas, comumente centradas na incapacidade de considerar os vieses de comportamento necessários à explicação das anomalias do mercado. Para Thaler e Shefrin (1981), um dos aspectos relevantes na tomada de decisão dos investidores, que parece ainda não ter sido considerado em pesquisas nacionais, é o senso de controle. Assim como em dietas criadas e impostas às pessoas, com o objetivo principal de controle de peso, existem iniciativas da indústria de produtos financeiros para convencer as pessoas a iniciar uma prática de investimentos, que busca romper a inércia dos indivíduos relativa ao procedimento de destinação de recursos à poupança pessoal, tendo em vista o senso de controle sobre a situação financeira pessoal, bem como a manutenção de seu estilo de vida futuro.

\section{Definição Conceitual do Senso de Controle}

O senso de controle tem sido entendido como a percepção, por parte de um indivíduo, de poder pessoal sobre o controle, o estabelecimento, e a direção para resultados e objetivos de vida. Muitos pesquisadores têm examinado o senso de controle mediante diversos construtos, entre os quais se destacam Wallston e Wallston (1981). Neste estudo, assim como no realizado por Schieman (2001, pp. 153-178), a medida de senso de controle utilizada tem suas bases em construtos como estes: fatalismo, instrumentalismo, e auto-eficácia (Gecas, 1989; Mirowsky \& Ross, 1990; Pearlin \& Schooler, 1978; Turner \& Roszell, 1994).

Pessoas com baixo senso de controle tendem a sentir-se com pouco poder, acreditam que as chances na vida são resultado de fatalidade, que os eventos são mais freqüentemente resultado da sorte, e ainda que têm baixo controle sobre coisas ruins que podem ocorrer em suas vidas. Pesquisas, como as realizadas por Mineka e Kelly (1991); Ormel e Sanderman (1991); e por Ross e Willigen (1997), têm documentado a significância do senso de controle para a percepção de bem-estar físico e mental, já que experiências mal sucedidas (como perdas inesperadas) tendem a desencadear sentimentos de arrependimento, e baixo senso de controle. Além disso, o senso de controle possibilita nos indivíduos, versatilidade na solução de problemas, bem como encaminhamento apropriado das emoções, por ocasião de decisões em eventos adversos, como aqueles relativos à sua vida futura (Clore, Ortony, Dienes, \& Fujita, 1993; Turner \& Roszell, 1994). O senso de controle tem sido apontado como aspecto particularmente crucial para as pessoas mais velhas, quando submetidas a contingências, devido a situações de perdas pessoais ou outras dificuldades.

No âmbito nacional, ainda é pequena a parcela da literatura acerca do senso de controle. Ao mesmo tempo, observa-se sensível concentração de pesquisas realizadas sobre o tema nos campos da medicina e da psicologia. Entre os trabalhos realizados no Brasil destacam-se os de Santos (2004, 2005), nos quais se exploram semelhanças e diferenças entre homens e mulheres, adultos e idosos, quanto ao senso de controle. Os principais achados relatados nessas pesquisas são que os indivíduos pertencentes às faixas etárias mais avançadas crêem menos fortemente na sua capacidade de controlar sua saúde e suas relações sociais. Adicionalmente, para Santos (2004), os indivíduos que menos crêem no próprio esforço como veículo de controle, são os que mais acreditam na sorte e no divinismo. E ainda, os mais velhos são os que menos crêem na possibilidade de controlar relações sociais e familiares, finanças e produtividade. Em contrapartida, os jovens atribuíram mais a si o controle da própria saúde e das relações sociais, quando comparados às pessoas pertencentes às faixas etárias mais avançadas. Esses aspectos, no âmbito brasileiro, também foram anteriormente estudados por Teixeira (2002). 


\section{Idade e Senso de Controle}

Para Gecas (1989) existe associação entre idade e senso de controle. Argumenta-se que o senso de controle cresce durante o início da vida adulta, atinge o auge na idade madura, e torna-se baixa entre os grupos de pessoas de idade mais avançada. De forma complementar, existem pesquisas que documentam níveis diferentes de senso de controle entre as diversas faixas etárias (Rodin, 1986, pp. 1271-1276). Alguns estudos mostram não existir diferenças de senso de controle entre jovens e pessoas de meia idade. Ao mesmo tempo, em outras pesquisas, como a realizada por Clark-Plaskie e Lachman (1999), verifica-se senso de controle maior nos adultos de meia idade, quando comparado a adolescentes. Desse modo, resultados inconlusivos quanto ao senso de controle entre pessoas de meia idade também foram encontrados por Lachman (1986).

No âmbito mundial tem-se atestado um baixo senso de controle entre as pessoas de terceira idade (Mirowsky, 1995; Mirowsky \& Ross, 1999; Sastry \& Ross, 1998; Schieman \& Turner, 1998). Acredita-se, porém, que a idade madura é tipicamente aquele período no qual as pessoas costumam imprimir um ritmo menos acelerado às suas atividades, e claramente se reduz o senso de controle; mas novamente as pesquisas a esse respeito mostram-se inconclusivas. Pesquisas mais recentes têm dedicado atenção ao estudo do senso de controle entre idosos. Assim, recentemente, Schieman, Pudrovska e Milkie (2005, pp. 165-196) estudaram o efeito da religiosidade sobre o senso de controle em indivíduos com idade superior aos 65 anos. Os resultados da pesquisa revelaram que os indivíduos atribuem os acontecimentos bons e ruins de suas vidas à vontade divina.

\section{Idade, Educação, e Senso de Controle}

A educação desempenha um significativo papel na associação entre idade e senso de controle, especialmente como mediador ou moderador. Existem evidências, relatadas na literatura, a respeito da associação positiva entre educação e controle (Gecas, 1989; Schieman \& Turner, 1998). Nesse contexto, Mirowsky (1995, p. 33) advogou que "education serves as an avenue to, and an element of, socioeconomic status. Thus it marks the social power that helps provide control over circumstances". Mas, para agir como um mediador, a educação precisa ser padronizada segundo a idade e estar associada ao senso de controle. Assim, Foner (1975) e Riley (1971) sugeriram uma estrutura para entender as associações entre educação, idade e senso de controle. Esses autores consideram a importância da idade cronológica, não de maneira absoluta, mas como indicador de experiências pessoais. Nas gerações passadas, a estrutura de ocupação requeria dos indivíduos menores níveis de educação para assumir responsabilidades. Por outro lado, contemporaneamente, níveis maiores de educação são necessários para o desenvolvimento de funções de maneira competitiva no mercado.

De forma alinhada com esse raciocínio, Lachman (1986) defendeu que os benefícios econômicos e psicológicos, derivados da educação, provavelmente são diferentes, em cada idade das pessoas. Uma extensão dessa idéia para o estudo do senso de controle: pessoas que alcançam idades mais avançadas, e ainda apóiam níveis melhores de educação, podem manter alto nível de senso de controle, quando submetidos a situações de perda, ou declínio de sua riqueza.

A educação pode, então, proporcionar capacidades individuais, como persistência, senso de efetividade, habilidade para resolver problemas, além de benefícios econômicos daí resultantes. A educação ainda aumenta a capacidade intelectual e cognitiva, que pode favorecer o senso individual de estar sendo um agente ativo em determinados momentos da vida (Ross \& Willigen, 1997). De forma similar a uma credencial de status e capacidade pessoal, a educação proporciona qualidades que podem proteger o indivíduo contra o declínio de seu senso de controle nas idades mais avançadas, Hipótese da Vantagem Acumulada. 


\section{Idade, Regras Sociais e Senso de Controle}

Alguns estudos, como o realizado por Pearlin e Skaff (1996), sugerem que as pessoas de idade mais avançada devem buscar adaptar-se às perdas associadas ao avanço da idade - e que o processo de adaptação pode influenciar qualidades pessoais, conjunto no qual se inclui o senso de controle. Padrões de idade nos papéis exercidos pelos indivíduos podem refletir-se em diferenças de controle. Por exemplo, experiências de pessoas mais jovens, no meio acadêmico, no mercado de trabalho, e na formação de família, aumentam o nível de ocupação e de expectativas correntes e responsabilidades.

O exercício de funções de empregados em tempo integral, ou mesmo estudantes, podem oferecer oportunidades de troca de experiências, essenciais à construção da auto-confiança e ao desenvolvimento de qualidades pessoais, tais como o senso de controle (Ross \& Willigen, 1997). De maneira consistente com esse raciocínio, Clark-Plakie e Lachman (1999) sugerem que adultos de meia idade enfatizam a importância do trabalho em suas vidas e que o destaque conferido ao trabalho é relacionado ao senso de controle.

Entretanto, tanto o status de desempregado ou de dona-de-casa pode ter conseqüências negativas para o bem-estar (Pearlin \& Skaff, 1996). Adicionalmente, a teoria dos papéis sociais propõe que o envelhecimento pode causar perda de poder, que se reflete no senso de controle. Assim, a aposentadoria, por exemplo, é questão central da vida madura (Neugarten \& Datan, 1996). Para Ross e Drentea (1998), a aposentadoria pode trazer conseqüências de liberação ou de alienação. A perda do trabalho por aposentadoria pode liberar o indivíduo para atividades de lazer. Em contraste, o desligamento da pessoa de seu trabalho remunerado pode influenciar negativamente seu senso de controle. Ademais, o trabalho remunerado reforça a associação entre esforço e resultado, um processo que aumenta o senso de controle (Mirowsky \& Ross, 1990). Para verificar a consistência desse raciocínio, Drentea (2002) examinou se o status de aposentado está associado à saúde mental, e como atividades diárias poderiam mediar essa associação. Os resultados apontam uma associação negativa entre o status de aposentado com o nível de senso de controle dos indivíduos pesquisados.

Outras circunstâncias pessoais e sociais podem ser destacadas. Insatisfação com a situação financeira pessoal pode afetar a percepção de saúde e o relacionamento interpessoal de um indivíduo (Mirowsky \& $\mathrm{Hu}, 1996)$. Schieman (1999) encontrou evidências de que, mesmo quando submetidas a baixos níveis de renda, pessoas mais velhas percebem menor dificuldade financeira. Por outro lado, durante os primeiros anos da vida adulta, muitos jovens estão envolvidos em atividades em que eles acumulam riqueza em ritmos vagarosos. Posteriormente, suas ocupações tornam-se mais consistentes e sólidas, capazes de oferecer maiores níveis de renda, contribuindo para o aumento do senso de satisfação com a situação financeira.

Diante disso, associando-se as idéias relativas à satisfação com as situações financeira, e de saúde, uma extensão para a interação da idade com o senso de controle torna-se possível. Primeiro, o padrão da própria saúde, relatado pelo indivíduo, contribuiria negativamente para o senso de controle entre os adultos mais velhos. Segundo, padrões de idade na satisfação com a situação financeira pessoal podem influenciar a associação de idade com o senso de controle, isto é, altos níveis de satisfação financeira entre adultos mais velhos podem dissimular o tamanho da associação idade-controle.

Além de educação, saúde, riqueza e participação social podem influenciar o senso de controle. A perda do trabalho e os papéis familiares podem compelir o indivíduo a buscar formas alternativas de filiação. A participação social nessa fase da vida é importante, exercendo papel crucial para adultos mais velhos. O envolvimento com a religião é um exemplo de tentativa de compensar a responsabilidade social e o senso de reciprocidade, contribuindo para o aumento da qualidade da integração social (Levin \& Chatters, 1998). Desse modo, o envolvimento religioso pode proporcionar um mecanismo de mitigação dos impactos emocionais que as adversidades inerentes à vida futura podem impor às famílias. Assim, esses argumentos sugerem que um maior envolvimento religioso entre os adultos mais velhos podem diminuir parte da associação negativa entre idade e senso de controle. $\mathrm{O}$ efeito da confiança e da reciprocidade, presentes nas relações sociais sobre o senso de controle, tem sido motivo de pesquisas que buscam comparar comportamentos de indivíduos em 
diferentes culturas. Hayashi, Ostrom, Walker e Yamagishi (1999) compararam os comportamentos indivíduos norte-americanos e japoneses, encontrando diferenças significativas do efeito das relações de reciprocidade e confiança mútua sobre o senso de controle.

Os esforços de pesquisa na área de finanças comportamentais, no âmbito nacional, ainda são embrionários e essencialmente concentrados nas conseqüências dos vieses cognitivos sobre os julgamentos realizados pelos agentes. No contexto da literatura brasileira que se liga ao tema, poucos trabalhos são encontrados, alguns foram realizados por Halfeld e Torres (2001); Marcon, Godoi, Barbosa e Pinto (2002); Kimura e Basso (2003); e Macedo (2003).

A respeito do excesso de confiança, destacadamente nos profissionais de finanças, Fonseca e $\mathrm{Yu}$ (2003, pp. 101-111) concluíram que a experiência acumulada tornou os indivíduos mais confiantes em suas previsões, e relativamente menos suscetíveis a mudanças de opinião. Por outro lado, a experiência não contribuiu para aumentar a proporção de acertos nas suas previsões. E mais ainda, a correlação negativa obtida indica que, quanto maior é a experiência do profissional, menor a probabilidade de acerto. Desse modo, foi constatado por esses autores que a maior confiança nas previsões, aliada ao menor índice de acertos, revela que os profissionais mais experientes (consequientemente com a idade mais avançada) apresentam maior excesso de confiança. Porém, em se tratando de pesquisas a partir da experiência brasileira, não foram encontrados estudos que busquem entender as associações dos vieses cognitivos com as características pessoais.

\section{PROCEDIMENTOS METOdOLÓGICOS}

\section{Amostra, Variáveis e Dados}

Os dados foram coletados por dois pesquisadores em um aeroporto de uma das capitais brasileiras, ao longo dos meses de fevereiro e março, do ano de 2006. Os indivíduos respondentes foram selecionados aleatoriamente. A cada um dos 421 respondentes (todos voluntários) foi aplicado um questionário (respeitando-se as disposições das Normas para Pesquisa Envolvendo Seres Humanos, Res. CNS no 196/96), com 13 questões, o qual estava estruturado em três conjuntos de perguntas fechadas (ver Apêndice A), em cuja construção se considerou a literatura disponível acerca do tema, como se explicita a seguir.

- Variáveis demográficas. Sexo foi codificada com valor $=1$ para casos femininos $(51,3 \%)$, e com 0 para os casos masculinos (48,7\%); Idade para indivíduos pesquisados está no intervalo de 15 a 77 anos $($ média $=29,94$, mediana $=25$, desvio padrão $=11,81)$; Educação foi medida pela quantidade total de anos de estudo (média $=17,76$; mediana $=18$; desvio padrão $=4,62$ ) e pelo nível de instrução formal (Mestrado ou Doutorado $=1,9 \%$, Especialização $=12,1 \%$, Graduação $=61 \%$, Médio $=23,5 \%$, Fundamental $=1,4$ ), etnia $($ branco $=59,4 \%$, Pardo $=24,9 \%$, Negro $=8,3 \%$, Amarelo $=6,4 \%$, Indígena $=1,0 \%)$; Status marital $($ Casado $=32,3 \%$, Nunca casou $=63,4 \%$, Divorciado ou Separado $=3,8 \%$, Viúvo $=0,5 \%)$, Status ocupacional (trabalha expediente integral $=$ $60,1 \%$, trabalha expediente parcial $=9,7 \%$, Estudante $=22,6 \%$, Dona(o)-de-casa $=2,1 \%$, Desempregado $=2,9 \%$ ).

- Outras características pessoais e sociais. Esse item buscava do indivíduo respostas aos itens que seguem: 'em relação à sua própria situação financeira atual você poderia dizer que está: 1) extremamente satisfeito, 2) mais ou menos satisfeito, 3) extremamente insatisfeito?'. As respostas foram dadas numa escala de 1 a 10, onde quanto mais próximo de 1 mais satisfeito, e quanto mais próximo de 10, mais insatisfeito (Média $=5,48$; Mediana $=5$; Desvio padrão $=2,13$ ). Na regressão múltipla foi utilizado o inverso das notas obtidas para essa pergunta, já que, ao contrário das outras duas variáveis desse grupo, a satisfação financeira está com a escala invertida no questionário, isto com o intuito reduzir o efeito distorcivo da repetição de notas para as outras variáveis. Outro item 
perguntava: 'Você diria que a sua saúde, em geral, é excelente, boa, razoável, ou pobre?'. As respostas a essa questão foram dadas numa escala de 10 pontos, onde quanto mais próxima de 1 indicavam pobre e mais próximas de 10 indicavam excelente (Média $=7,95$; Mediana $=8,00$; Desvio padrão $=1,59)$. Uma terceira e última pergunta neste bloco era: 'Com que freqüência você recorre à utilização de serviços religiosos - missas, cultos ecumênicos, encontros e similares?'. $\mathrm{O}$ intervalo de escolhas foi de 0 (nunca) até 8 (várias vezes por semana), com Média $=2,89$, Mediana $=3,00$, Desvio padrão $=2,20$.

Índice de senso de controle. Foi construído a partir das respostas recebidas quanto à concordância ou discordância em relação a argumentos como se seguem: (a) Eu não tenho muito hábito de planejar as coisas; se algo bom tem de acontecer acontecerá. (b) A maioria das vezes os meus problemas são devidos a acontecimentos ocorridos. (c) As coisas realmente boas que ocorrem comigo são resultado de muita sorte. (d) Eu tenho pouco controle sobre as ruins coisas que acontecem comigo (Mirowsky \& Ross, 1991). O intervalo de respostas foi de 1 (concordo totalmente) a 10 (discordo totalmente). Esses itens foram somados para formar um índice, que varia no intervalo de 4 a 40 (Média = 28,23; Mediana = 29; Desvio padrão = 6,43; Mínimo $=4$; Máximo $=40$ ); altos scores refletem maior senso de controle (consistência interna medida pelo Alfa de Cronbach $=0,695$ ).

\section{O Modelo}

As idéias anteriormente colocadas convergem para a assunção da existência de uma relação parabólica do tipo $\mathbf{U}$ invertido entre idade e senso de controle. Então, espera-se que o coeficiente do termo linear da idade seja positivo e significativo, e que o seu termo quadrático tenha seu coeficiente menor que zero. De forma complementar, a expectativa é de que o déficit de senso de controle, iniciado após certa idade ótima, na qual se espera verificar o senso de máximo, ocorra de forma acelerada. Dito de outra forma, o senso de controle, ao longo da vida cresceria a taxas decrescentes, e após certa idade ótima, decresceria a taxas crescentes, assumindo-se, porém, que este fenômeno seja mediado por aspectos demográficos e sociais relativos a cada indivíduo. Para interpretação de modelos de regressão polinomial, caso que se aplica a este trabalho, é importante observar que o efeito parcial estimado deve ser determinado, tomando a derivada da variável dependente (senso de controle) com relação à variável independente. Tendo em vista o objetivo deste artigo, o efeito parcial da idade sobre o senso de controle, isoladas as outras variáveis independentes consideradas, é dado por:

$$
\frac{\partial \text { Senso_de_controle }}{\partial \text { Idade }}=\beta_{\text {Idade_linear }}+2 \beta_{\text {Idade_quadrático }} \times \text { Idade }
$$

\section{RESULTADOS ALCANÇADOS}

Antes de iniciar a discussão dos coeficientes estimados para a regressão múltipla, examina-se a existência de correlação entre as variáveis estudadas, o que está ilustrado na Tabela 1. Entre as 9 variáveis independentes utilizadas, as que mais apresentaram correlações significativas foram Idade e Envolvimento religioso. À luz dos coeficientes de correlação encontrados, parece que os indivíduos pertencentes às faixas etárias mais avançadas possuem maior tempo dispensado à educação, tendem a possuir o estado civil casado, estão mais satisfeitos com sua situação financeira, são mais envolvidos em eventos religiosos, porém apresentam maior insatisfação com sua própria saúde. No entanto as pessoas de maior envolvimento com eventos religiosos são mais freqüentemente do sexo feminino, tendem a pertencer ao estado civil casado e a possuir menor nível de educação. 
Tabela 1: Matriz de Correlação entre as Variáveis Independentes Estudadas

\begin{tabular}{|c|c|c|c|c|c|c|c|c|}
\hline Variáveis & 1 & 2 & 3 & 4 & 5 & 6 & 7 & 8 \\
\hline 1. Idade & - & & & & & & & \\
\hline 2. Sexo & -0.035 & & & & & & & \\
\hline 3. Etnia & -0.074 & $-0.090^{*}$ & & & & & & \\
\hline 4. Educação & $0.114^{* * *}$ & -0.007 & $0.089^{*}$ & & & & & \\
\hline 5. Status marital & $0.645^{* * *}$ & -0.008 & -0.029 & $0.167^{* / 4}$ & & & & \\
\hline 6. Status ocupacional & $0.190^{* * * \%}$ & $-0124^{* * \pi}$ & 0.008 & $0.183^{\text {***; }}$ & $0.262^{*}$ & & & \\
\hline 7. Satisfação financeira & 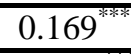 & -0.075 & 0.074 & $0.108^{\text {kF }}$ & $0.131^{* * * * *}$ & 0.071 & & \\
\hline 8. Satisfação com saúde & $-0.177^{* * *+1}$ & -0.019 & 0.062 & -0.017 & $-0.093^{*}$ & 0.029 & 0.049 & \\
\hline 9. Envolvimento religioso & $0.222^{* * * *}$ & $0.155^{\text {***6 }}$ & $-0.162^{* * *}$ & $-0.127^{\text {*** }}$ & $0.094^{*}$ & -0.018 & 0.052 & -0.033 \\
\hline
\end{tabular}

i) Variáveis demográficas. Sexo (valor $=1$ para casos femininos e com 0 para os casos masculinos). Idade em anos. Educação foi medida pela quantidade total de anos de estudo. Etnia (branco $=1$, demais $=0)$. Status marital $($ Casado $=1$, demais $=0)$, Status ocupacional (Regime de trabalho integral $=1$, demais $=0$ ). ii) Outras características pessoais e sociais. Esse item buscava do indivíduo repostas aos itens que se seguem: 'em relação à sua própria situação financeira atual você poderia dizer que está: 1) extremamente satisfeito; 2) mais ou menos satisfeito; 3) extremamente insatisfeito?'. As respostas foram dadas numa escala de 1 a 10, onde quanto mais próximo de 1 mais satisfeito, e quanto mais próximo 10, mais insatisfeito. Na regressão múltipla foi utilizado o inverso das notas obtidas para essa pergunta. Satisfação com a própria saúde: 'Você diria que a sua saúde, em geral, é excelente, boa, razoável, ou pobre?' As respostas a essa questão foram dadas numa escala de 10 pontos, onde quanto mais próxima de 1 indicavam pobre e mais próximas de 10 indicavam excelente. Envolvimento religioso: o intervalo de escolhas foi de 0 (nunca) até 8 (várias vezes por semana).

Notas: i) ${ }^{* * * *}$ Significativo a $1 \% ;{ }^{* *}$ Significativo a $5 \%$; ${ }^{*}$ Significativo a $10 \%$; ii) $\mathrm{N}=421$; iv) Esta tabela apresenta a matriz de correlação entre as variáveis independentes estudadas; v) As variáveis, dependente e independente, estão definidas em detalhes na subseção 3.1 .

Fonte: elaborado pelo autor a partir dos dados da pesquisa.

A Tabela 2 ilustra os resultados obtidos para a regressão múltipla, com a variável dependente sendo o senso de controle. Assim, verificam-se os parâmetros estimados para cinco equações, utilizando-se as variáveis independentes relativas a dados demográficos, e características pessoais e sociais, conforme já detalhado na terceira seção. 
Tabela 2: Parâmetros Estimados Para a Regressão Múltipla

\begin{tabular}{|c|c|c|c|c|c|}
\hline Variável & Equação (1) & Equação (2) & Equação (3) & Equação (4) & Equação (5) \\
\hline \multirow[t]{2}{*}{ Idade } & $1,581^{* * * *}$ & $1,160^{* * * *}$ & $1,195^{* * *}$ & $0,795^{* * * *}$ & $0,748^{* * * *}$ \\
\hline & $(32,931)$ & $(12,811)$ & $(12,642)$ & $(6,254)$ & $(5,429)$ \\
\hline \multirow[t]{2}{*}{ Idade $^{2}$} & $-0,019^{* * *}$ & $-0,014^{* * *}$ & $-0,014^{* * *}$ & $-0,009^{* * *}$ & $-0,008^{* * *}$ \\
\hline & $(-21,949)$ & $(-11,086)$ & $(-10,409)$ & $(-5,287)$ & $(-3,232)$ \\
\hline \multirow[t]{2}{*}{ Sexo $($ feminino $=1)$} & $-0,576$ & $-0,357$ & $-0,508$ & $-0,642$ & $-0,810$ \\
\hline & $(-0,804)$ & $(-0,499)$ & $(-0,701)$ & $(-0,898)$ & $(-1,091)$ \\
\hline \multirow[t]{2}{*}{ Etnia $($ branco $=1)$} & $1,276^{*}$ & 0,756 & 0,679 & 0,344 & 0,024 \\
\hline & $(1,752)$ & $(1,032)$ & $(0,932)$ & $(0,476)$ & $(0,031)$ \\
\hline \multirow[t]{2}{*}{ Educação } & & $0,429^{* * *}$ & $0,426^{* * *}$ & $0,393^{* * *}$ & $0,848^{* * *}$ \\
\hline & & $(5,389)$ & $(5,382)$ & $(4,998)$ & $(5,296)$ \\
\hline \multirow[t]{2}{*}{ Status marital $($ casado $=1)$} & & & $-2,239^{* *}$ & $-1,319$ & $-0,367$ \\
\hline & & & $(-2,261)$ & $(-1,340)$ & $(-0,347)$ \\
\hline Regime de trabalho (tempo & & & $-0,530$ & $-0,401$ & $-0,714$ \\
\hline integral = 1) & & & $(-0,667)$ & $(-0,517)$ & $(-0,885)$ \\
\hline \multirow[t]{2}{*}{ Satisfação com situação financeira } & & & & $-0,395$ & $-0,690$ \\
\hline & & & & $(-0,186)$ & $(-2,293)$ \\
\hline \multirow[t]{2}{*}{ Satisfação com a própria saúde } & & & & $0,934^{* * *}$ & $0,708^{* * *}$ \\
\hline & & & & $(4,807)$ & $(3,290)$ \\
\hline \multirow[t]{2}{*}{ Envolvimento religioso } & & & & 0,004 & 0,029 \\
\hline & & & & $(0,024)$ & $(0,167)$ \\
\hline \multirow[t]{2}{*}{ Idade_Educação } & & & & & $-0,015^{* * *}$ \\
\hline & & & & & $(-3,551)$ \\
\hline \multirow[t]{2}{*}{ Idade $^{2}$ Educação } & & & & & $0,000^{*}$ \\
\hline & & & & & $(0,47)$ \\
\hline Coeficiente de determinação $\left(\mathrm{R}^{2}\right)$ & 0,936 & 0,943 & 0,944 & 0,947 & 0,948 \\
\hline
\end{tabular}

i) Variáveis demográficas. Sexo (valor $=1$ para casos femininos e com 0 para os casos masculinos); Idade em anos; Educação foi medida pela quantidade total de anos de estudo; Etnia (branco $=1$, demais $=0)$; Status marital $($ Casado $=1$, demais $=0$ ), Status ocupacional (Regime de trabalho integral $=1$, demais $=0$ ). ii) Outras características pessoais e sociais. Esse item buscava do indivíduo repostas aos itens que se seguem: 'em relação à sua própria situação financeira atual você poderia dizer que está: 1) extremamente satisfeito; 2) mais ou menos satisfeito; 3) extremamente insatisfeito?' As respostas foram dadas numa escala de 1 a 10, onde quanto mais próximo de 1 mais satisfeito, e quanto mais próximo 10, mais insatisfeito. Na regressão múltipla foi utilizado o inverso das notas obtidas para essa pergunta. Satisfação com a própria saúde: 'Você diria que a sua saúde, em geral, é excelente, boa, razoável, ou pobre?'. As respostas a essa questão foram dadas numa escala de 10 pontos, onde quanto mais próxima de 1 indicavam pobre e mais próximas de 10 indicavam excelente. Envolvimento religioso: o intervalo de escolhas foi de 0 (nunca) até 8 (várias vezes por semana). iii) Índice de senso de controle. Foi construído a partir das respostas recebidas quanto à concordância ou discordância em relação a argumentos como se seguem: (a) não existe muito hábito de planejar - se algo bom tem de acontecer; (b) muitos dos meus problemas são devidos a acontecimentos ruins ocorridos; (c) as coisas realmente boas ocorrem comigo por causa de muita sorte; (d) eu tenho pouco controle sobre as coisas que acontecem comigo. O intervalo de respostas foi de 1 (concordo totalmente) a 10 (discordo totalmente). Esses itens foram somados para formar um índice, que varia no intervalo de 4 a 40.

Notas: i) Coeficientes não padronizados (Estatística t); ii) ${ }^{* * *}$ Significativo a $1 \%$; ${ }^{* *}$ Significativo a $5 \%$; ${ }^{*}$ Significativo a $10 \%$; iii) $\mathrm{N}=421$; iv) Esta tabela apresenta os resultados obtidos na regressão pelo método dos mínimos quadrados ordinários, tendo como variável dependente o Índice de Senso de Controle. v) As variáveis, dependente e independentes estão definidas com mais detalhes na subseção 3.1. vii) $\mathrm{O}$ termo de intercepto foi supresso, tendo em vista não ter sido significativo. viii) Atenção deve ser dispensada à interpretação do coeficiente de determinação $\mathrm{R}^{2}$ já que, em modelos sem o intercepto, mesmo variando de 0 a 1, seu significado pode não ser o mesmo (Gujarati, 2000). Fator de Inflação da Variância [FIV] $<5,00$.

Fonte: elaborado pelo autor a partir dos dados da pesquisa.

Segundo os resultados obtidos para a equação 1, ilustrados na Tabela 2, um coeficiente linear positivo e um quadrático negativo para a Idade, ajustados por etnia e sexo, indicam uma associação parabólica entre idade e senso de controle. Conforme mostra a Figura 1, o senso de controle aumenta, a taxas desaceleradas, até aproximadamente os 41 anos. Isto é, fazendo a derivada nula: $-1,581 / 2[(-$ $\left.1,900) 10^{-2}\right]=41,60$, já que, segundo os resultados obtidos para a equação (1), assumiu-se:

$$
\frac{\partial S e n s o \_d e \_c o n t r o l e}{\text { IIdade }}=1,581-2 \times 1,9 \times 10^{-2} \text { Idade }
$$




\section{Figura 1: Relação Quadrática entre a Idade e o Senso de Controle segundo o Status Marital dos Indivíduos Pesquisados}

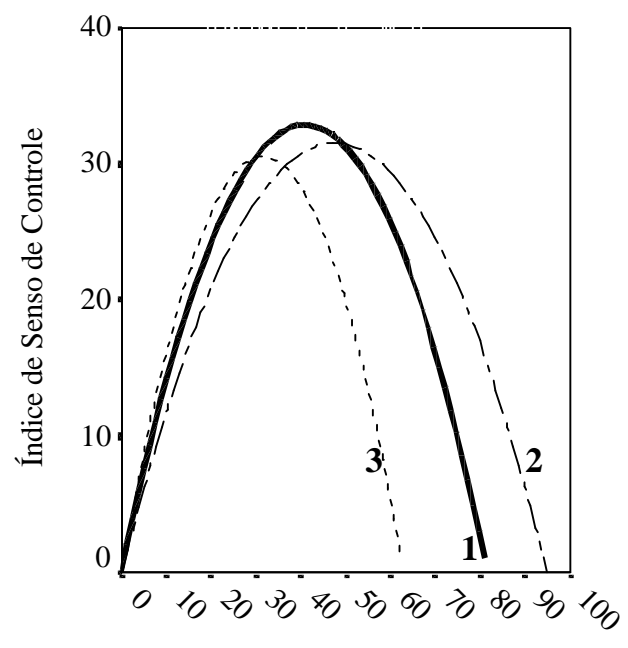

Idade

Nota: a curva 1 ilustra o comportamento do senso de controle em relação à idade, tomando como referência da amostra completa; a curva 2 refere-se aos respondentes casados; e a curva 3 é relativa aos respondentes não casados.

Fonte: elaborado pelos autores a partir dos dados da pesquisa.

Esse tipo de relação quadrática entre idade e senso de controle é consistente com a verificada no trabalho de Schieman (2001, p. 165); porém a idade que maximiza o senso de controle, nesse último estudo, é de aproximadamente 49 anos, ressaltando-se que a pesquisa foi conduzida com dados relativos a 1.421 indivíduos voluntários, nos Estados Unidos, no ano de 1996.

Acima dos 42 anos, o senso de controle tende a diminuir a taxas aceleradas, até atingir níveis mais baixos entre os respondentes de idade mais avançada. A análise da regressão desenvolve-se com a inclusão das outras variáveis independentes consideradas na pesquisa. Desse modo, buscando entender os efeitos da idade sobre o senso de controle, mediante a influência de outros fatores, são confrontados os coeficientes dos termos linear ( $\beta_{\text {Idade }}=1,581 ; \mathrm{t}=32,931 ; \mathrm{Sig}<0,01$, na equação 1$)$ e quadrático da idade $\left(\beta_{\text {Idade }}{ }^{2}=-0,019 ; \mathrm{t}=-21,949 ; \mathrm{Sig}<0,01\right)$ com os obtidos no ajustamento progressivo da variáveis mediadoras, isto é, comparando-se os coeficientes obtidos nas equações (1), (2), (3), (4), e (5).

Para estimar o impacto da educação (equação 2), status marital (equação 3), e satisfação com as situações financeira e de saúde, além de envolvimento religioso, testou-se a equação 4. Para testar a hipótese da vantagem acumulada, ou educação como um moderador, foram incluídos um termo de interação linear e outro quadrático da educação com a idade (equação 5). Para a educação mediar a associação entre idade e controle, necessita estar relacionada ao controle e padronizada pela idade na mesma direção. A equação 2 da Tabela 2 mostra que a educação está positivamente associada ao controle $\left(\beta_{E d u c}=0,429 ; \mathrm{t}=5,389 ; \mathrm{Sig}<0,01\right)$.

A Figura 2 ilustra que a idade associada à educação reflete diferenças de senso de controle segundo a idade. 
Figura 2: Médias da Educação e do Senso de Controle através dos Grupos de Idade

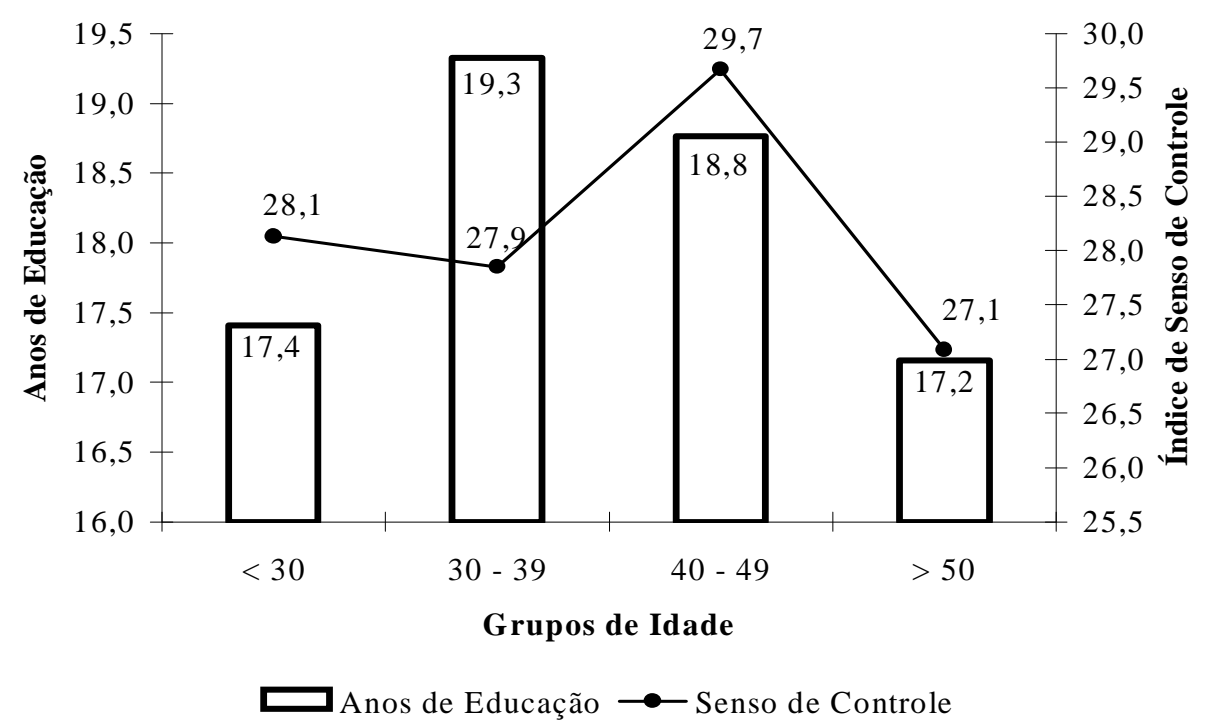

Fonte: elaborado pelos autores a partir dos dados da pesquisa.

Assim, é razoável assumir a possibilidade de que a educação contribua para alguma associação com o controle. De fato, a inclusão da educação reduz a magnitude do coeficiente linear de 1,581 para 1,160 , aproximadamente $36,7 \%$, e o coeficiente quadrático da idade de $-0,019$ para $-0,014$, aproximadamente. Esse resultado é consistente com os achados obtidos por Schieman (2001, pp. 153178). A idéia das regras sociais assume que padrões de idade segundo o status marital e de ocupação podem contribuir para diferenças do senso de controle. A Figura 3 ilustra a diferença de valores médios de senso de controle segundo o nível de instrução formal e o status marital; verificam-se valores maiores para os indivíduos de maior nível de instrução, assim como também para os respondentes casados.

Os resultados obtidos para a equação 4 na Tabela 2 indicam que a satisfação financeira não se mostrou associada ao senso de controle $\left(\beta_{\text {Situaç̃o Financeira }}=-0,395 ; \mathrm{t}=-0,186 ; \mathrm{Sig}>0,1\right)$, assim como o envolvimento religioso $\left(\beta_{\text {Envolvimento Religioso }}=0,004 ; \mathrm{t}=0,024 ; \mathrm{Sig}>0,1\right)$. No entanto, a satisfação com a saúde própria mostrou associação positiva com o senso de controle $\left(\beta_{\text {Saúde }}=0,934 ; \mathrm{t}=4,807\right.$; $\mathrm{Sig}<$ 0,01), resultado consistente com os argumentos desenvolvidos por Langer e Rodin (1976), os quais defendem uma associação positiva entre senso de controle e saúde do indivíduo. 
Figura 3: Senso de Controle segundo o Nível de Instrução e Status Marital
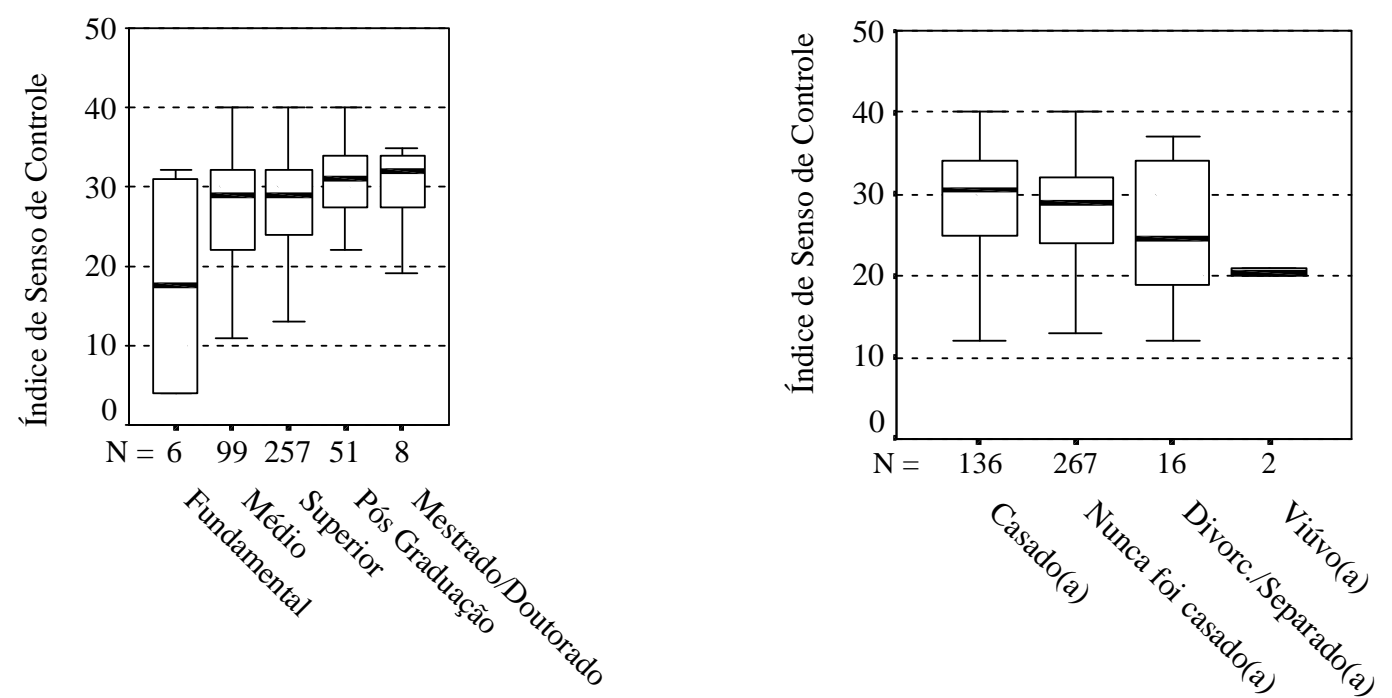

Fonte: elaborado pelos autores a partir dos dados da pesquisa.

A expectativa era que níveis mais elevados de satisfação financeira e de envolvimento religioso pudessem atenuar a associação negativa entre idade e senso de controle, o que não foi verificado à luz dos resultados obtidos. Por outro lado, maiores níveis de insatisfação com a saúde geral contribuiriam para um menor nível de senso de controle entre as pessoas de idade mais avançada. Comparando-se os resultados obtidos na equação 3 e na equação 4, nota-se uma diminuição da magnitude dos coeficientes linear, de 1,195 para $0,795(\Delta \% \approx 33,47)$ e quadrático da idade dos indivíduos, de $-0,014$ para $-0,009(\Delta \% \approx 78,04)$. Adicionalmente, parece que os indivíduos com idade mais avançada, além de relatarem menor satisfação com a própria saúde, tendem a sentir maior satisfação com a situação financeira (conforme Modigliani \& Brumber, 1954), bem como o envolvimento em atividades religiosas, conforme ilustra a Figura 4.

Figura 4: Scores das Médias Padronizadas da Satisfação financeira, Saúde Geral, e Envolvimento Religioso através dos Grupos de Idade

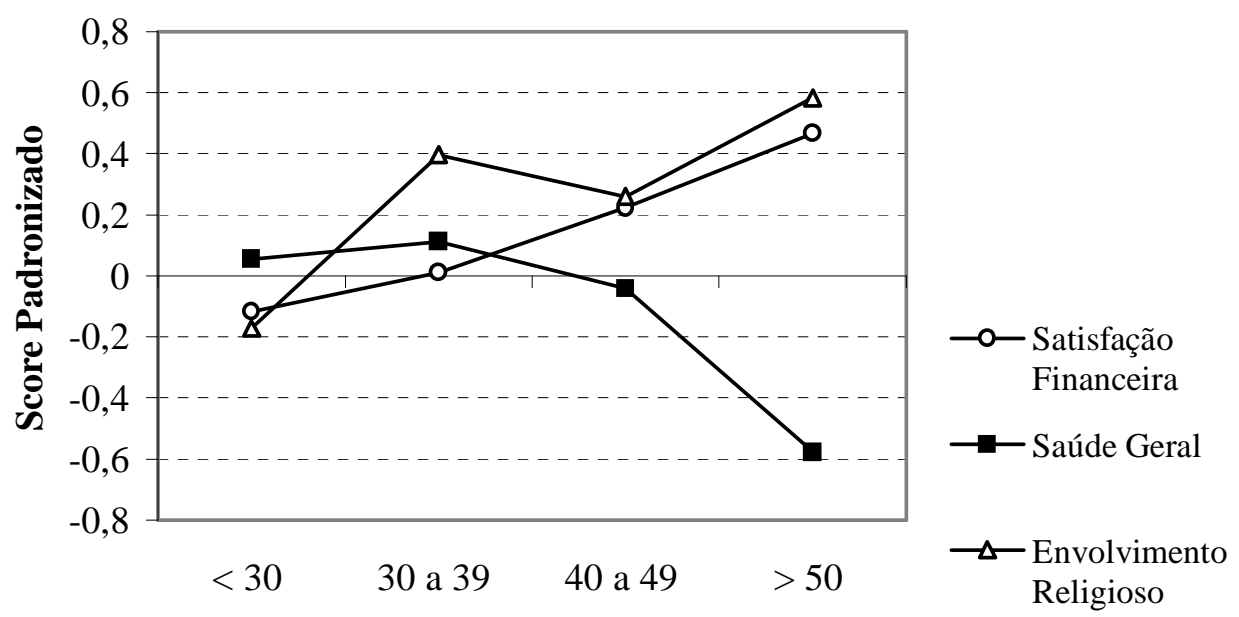

Grupos de Idade (anos)

Nota: os valores relativos à satisfação financeira, saúde geral e envolvimento religioso nesta figura são os scores padronizados da média.

Fonte: elaborado pelos autores a partir dos dados da pesquisa. 
Também após os 40 anos parece que há uma tendência de aumento do envolvimento religioso e da insatisfação com a saúde, de modo geral. Porém a satisfação financeira mostrou certa melhora com o aumento da idade. Um aspecto que deve ser destacado em relação à satisfação financeira é a média de idade dos indivíduos que alegaram possuir investimentos para momentos de crise financeira. Após realização de um teste $\mathrm{t}$ para igualdade de média para a idade das pessoas, segundo a posse de investimentos pessoais (27,28 anos), verificou-se que a idade daqueles que não o fazem é significativamente $(\operatorname{Sig}<0,01 ; \mathrm{t}=6,841)$ inferior à dos indivíduos na situação alternativa $(35,38$ anos). Em outras palavras, provavelmente o fato de possuir recursos investidos em ativos, o que pode favorecer maiores níveis de satisfação financeira, colabora para o aumento do senso de controle dos indivíduos nas faixas etárias mais avançadas.

Para testar a existência de vantagem acumulada (ou educação como moderador), assim como em Schieman (2001, p. 165), foram incluídos no modelo (equação 5) dois termos de interação da idade com a educação, um linear, Idade_Educ $c_{i}=I_{d a d e_{i}}{ }^{*} E d u c_{i}$, e outro quadrático, Idade ${ }^{2} E d u c_{i}=$ $I d a d e_{i}{ }^{2} * E d u c_{i}$, onde: $I d a d e_{i}=$ idade de um indivíduo $i$ em anos; $E d u c_{i}=$ tempo total de educação, em anos; que um indivíduo $i$ possui. A intenção é capturar o efeito da educação continuada ao longo da vida. Assim, à medida que o indivíduo é incluído em faixas etárias mais avançadas, espera-se que também tenha acumulado mais tempo total dispensado a atividades ligadas à educação, o que se espera que reduza o déficit do senso de controle com o avanço da idade.

Como se mostra na equação 5 da Tabela 2 , tanto o termo linear $\left(\beta_{\text {Idade_Educ }}=-0,015 ; \mathrm{t}=-3,551 ;\right.$ Sig $<$ $0,01)$, quanto o quadrático $\left(\beta_{\text {Idade_Educ }}^{2} 0,000 ; \mathrm{t}=0,47 ; \mathrm{Sig}<0,1\right)$ são estatisticamente significativos. $\mathrm{O}$ coeficiente negativo do termo linear de $I d a d e^{*} E d u c_{i}$ indica uma convergência na linha de regressão durante o início da vida adulta. O sinal positivo do coeficiente de $I d a d e^{2 *} E d u c_{i}$ indica divergência na linha de regressão durante o período mais avançado da vida adulta. Dito de outra forma, maiores níveis de educação aumentam o controle através da idade, isto é, a educação protege as pessoas da erosão do senso controle nas faixas etárias mais avançadas. Alternativamente, níveis menores de educação aumentam o risco de baixo senso de controle entre pessoas mais velhas. Esses resultados apóiam a hipótese da vantagem acumulada, e são consistentes com os obtidos por Schieman (2001).

\section{CONSIDERAÇÕES FINAIS}

O melhor entendimento dos erros de cognição, que influenciam o comportamento dos agentes, em face da tomada de decisões, constitui matéria essencial para explicar fenômenos financeiros; orientar a composição de políticas públicas; bem como apoiar o estabelecimento de estratégias de ação para as empresas. Então, a partir de dados relativos a 421 questionários aplicados em um aeroporto de capital brasileira, testou-se a associação da idade com o senso de controle, aspecto relevante para melhor conhecimento de vieses cognitivos, como o excesso de confiança e a procrastinação, em julgamentos realizados pelas pessoas, por ocasião da tomada de decisões.

A principal contribuição deste estudo é o fornecimento de elementos para o entendimento do senso de controle ao longo da vida do indivíduo, o que, pelo menos segundo a literatura, ainda não tem sido explorado no âmbito nacional. Os principais resultados alcançados são dois. Primeiro, à luz dos dados coletados, conforme expectativa, encontrou-se uma relação quadrática do tipo $\mathbf{U}$ invertido entre a idade dos indivíduos e o senso de controle, isto é, tanto as pessoas mais jovens, quanto as de faixas etárias mais avançadas, tendem a apresentar menores níveis de senso de controle, quando comparadas àqueles indivíduos com idade próxima de um adulto jovem, resultado consistente com os achados de Schieman (2001).

Em segundo lugar, a análise multivariada dos dados aponta um efeito mediador da associação entre a idade e o senso de controle, exercido por variáveis demográficas e sociais. Desse modo, a educação e a percepção de saúde, reportada pelos indivíduos pesquisados, mostraram-se elementos mediadores da associação entre a idade e o senso de controle. Em outras palavras, em média, as pessoas que alcançam 
faixas etárias mais avançadas, conservando bom nível de educação como de saúde, tendem a apresentar maiores níveis de senso de controle.

Algumas limitações inerentes a esta pesquisa devem ser citadas. (i) O conjunto de indivíduos participantes da pesquisa foi composto mediante limitações de recursos. (ii) Conforme ilustra o Apêndice $\mathrm{B}$, a distribuição de respondentes mediante idade e nível de instrução é resultado da amostragem aleatória, podendo não refletir um estrato adequado da população brasileira. Um aspecto a ser registrado, pelo menos na ótica dos autores deste artigo, é a inexistência de estudos similares no Brasil, em cujas argumentações centrais se poderia, neste estudo, apoiar-se para o estabelecimento de contraposições ou confirmações de achados, aspecto essencial para ratificar os resultados alcançados neste trabalho.

As questões acima colocadas juntam-se a outras relativas à literatura das finanças comportamentais e oferecem um promissor campo de trabalho. Desse modo, para pesquisas futuras pode-se sugerir: i) replicação deste estudo, considerando amostras diferentes; ii) incorporação de outros conceitos ou construtos para o senso de controle, ressaltando sua convergência ou divergência em relação aos achados aqui relatados; iii) verificação de associações entre perfil demográfico e social dos indivíduos e incorrência em erros cognitivos.

\section{Artigo recebido em 03.05.2006. Aprovado em 19.03.2007.}

\section{REFERÊNCIAS BIBLIOGRÁFICAS}

Aizcorbe, A. M., Kennickell, A. B., \& Moore, K. B. (2003). Recent changes in U.S. family finances: evidence from the 1998 and 2001 survey of consumer finances. Federal Reserve Bulletin, 89(1). $1-32$.

Bazerman, M. H. (2002). Judgment in managerial decision making (5th ed.). New York: Willey.

Bazerman, M. H. (2004). Processo decisório. São Paulo: Campus.

Buchanan, D., \& Huczynski, A. (2004). Organizational behaviour: an introductory text (5th ed.). Harlow, England: Prentice Hall.

Clark-Plaskie, M., \& Lachman, M. E. (1999). The sense of control in midlife. In S. Willis \& J. Reid (Eds.). Life in the middle: psycholosocial and social development in middle age. San Diego: Academic Press.

Clore, G. L., Ortony, A., Dienes, B., \& Fujita, F. (1993). Where does anger dwell? In R. Wyer Jr. \& T. K. Srull (Eds.). Advances in social cognition (Vol. 6, pp. 57-87). Hillsdale, NJ: Lawrence Erbaum.

Drentea, P. (2002). Retirement and mental health. Journal of Aging and Health, 14(2), 167-194.

Employee Benefit Research Institute. (2003). Retirement confidence survey: a summary of results. Recuperado em 15 abril, 2007, de http://www.ebri.org/rcs/2003/03rcssof.pdf

Fisher, K. L., \& Statman, M. (2000). Cognitive biases in market forecasts: the frailty of forecasting. Journal of Portfolio Management, 27(1), 72-81.

Fiske, S. T., \& Taylor, S. E. (1991). Social cognition. New York: McGraw-Hill.

Foner, A. (1975). Age in society: structure and change. American Behavioral Scientist, 19(2), 144165. 
Fonseca, C. F., \& Yu, A. S. O. (2003). Todos acima da média: excesso de confiança em profissionais de finanças. Revista de Administração, 38(2), 101-111.

Gecas, V. (1989). The social psychology of self-efficacy. Annual Review of Sociology, 15, 291-316,

Gujarati, D. N. (2000). Econometria básica. São Paulo: Makron Books.

Halfeld, M., \& Torres, F. F. L. (2001). Finanças comportamentais: aplicações no contexto brasileiro. Revista de Administração de Empresas, 41(2), 64-71.

Hayashi, N., Ostrom, E., Walker, J., \& Yamagishi, T. (1999). Reciprocity, trust, and the sense of control: a cross-societal study. Rationality and Society, 11(1), 27-46.

Kahneman, D., \& Tversky, A. (1972). Subjective probability: a judgement of representativeness. Cognitive Psychology, 3(3), 430-454.

Kahneman, D., \& Tversky, A. (1979). Prospect theory: an analysis of decision under risk. Econometrica, 47(2), 263-292.

Kimura, H., \& Basso, L. F. C. (2003, setembro). Finanças comportamentais: investigação do comportamento decisório dos agentes brasileiros. Anais do Encontro Nacional dos Programas de Pós-Graduação em Administração, Atibaia, SP, Brasil, 27.

Lachman, M. E. (1986). Personal control in later life: stability, change, and cognitive correlates. In M. M. Baltes \& P. B. Baltes (Eds.). Psychology of control and aging (pp. 207-236). New Jersey: Lawrence Erbaum.

Langer, E. J., \& Rodin, J. (1976). The effects of choice and enhanced personal responsibility for the aged: a field experiment in an institutional setting. Journal of Personality and Social Psychology, 34(2), 191-198.

Levin, J. S., \& Chatters, L. M. (1998). Religion, health, and psychological well-being in older adults. Journal of Health and Aging, 10(4), 504-531.

Lichtenstein, S., Fischhoff, B., \& Phillips, L. (1982). Calibration of probabilities: the state of the art to 1980. In D. Kahneman \& A. Tversky (Eds.). Judgement under uncertainty: heuristics and biases (pp. 306-334). Cambridge: Cambridge University Press.

Macedo, J. S. M., Jr. (2003). Teoria do prospecto: uma investigação utilizando simulação de investimentos. Tese de doutorado, Universidade Federal de Santa Catarina, Florianópolis, SC, Brasil.

Marcon, R., Godoi, C. K., Barbosa, A., \& Pinto, C. R. (2002, outubro). Análise do sentimento de aversão à perda em finanças comportamentais e na teoria psicanalítica. Anais do Congresso Latino Americano de Escolas de Administração, Porto Alegre, RS, 37.

Mas-Colell, A., Whinston, M. D., \& Green, J. R. (1995). Microeconomic theory. New York: Oxford University Press.

Mineka, S., \& Kelly, K. A. (1991). The relationship between anxiety, lack of control and loss of control. In A. Steptoe \& A. Appels (Eds.). Stress, personal control and health (pp. 163-192). Chichester: John Willey.

Mirowsky, J. (1995). Age and sense of control. Social Psychology Quarterly, 58(1), 31-43.

Mirowsky, J., \& Hu, P. N. (1996). Physical impairment and the diminishing effects of income. Social Forces, 74(3), 1073-7096. 
Mirowsky, J., \& Ross, C. E. (1990).Control or defense? Depression and the sense of control over good and bad outcomes. Journal of Health and Social Behavior, 31(1), 71-86.

Mirowsky, J., \& Ross, C. E. (1991) Eliminating defense and agreement bias from measures of the sense of control: a 2x2 index. Social Psychology Quarterly, 54(2), 127-145.

Mirowsky, J., \& Ross, C. E. (1999). Well-being across the life course. In A. V. Horwitz \& T. L. Scheid (Eds.). Handbook for the study of mental health: social contexts, theories, and systems. Cambridge, UK: Cambridge University Press.

Modigliani, F., \& Brumberg, R. (1954). Utility analysis and the consumption function: an interpretation of cross-section data. In K. K. Kurihara (Ed.). Post-keynesian economics. New Brunswick, NJ: Rutgers University Press.

Neugarten, B. L., \& Datan, N. (1996). Sociological perspectives on the life cycle. In D. A. Neugarten (Ed.). Meanings of age (pp. 96-113). Chicago: The University of Chicago Press.

Ormel, J., \& Sanderman, R. (1991). Life events, personal control and depression. In A. Steptoe \& A. Appels (Orgs.). Stress, personal control and health. Chichester: John Wiley.

Pearlin, L. I., \& Schooler, C. (1978). The structure of coping. Journal of Health and Social Behavior, $19(1), 2-21$.

Pearlin, L. I., \& Skaff, M. M. (1996). Stress and life course: a paradigm alliance. The Gerontologist, $36(2), 239-247$.

Plous, S. (1993). The psychology of judgment and decision making. New York: McGraw-Hill.

Riley, M. W. (1971). Social gerontology and the age stratification of society. The Gerontologist, 11(1), 79-87.

Rodin, J. (1986). Aging and health: effects of the sense of control. Science, 233(6), 1271-1276.

Ross, C., \& Willigen, M. van (1997). Education and the subjective quality of life. Journal of Health and Social Behavior, 38(3), 275-297.

Ross, C. E., \& Drentea, P. (1998). Consequences of retirement activities for distress and the sense of control. Journal of Health and Social Behavior, 39(4), 317-334.

Santos, A. T. (2004). Controle percebido, senso de auto-eficácia e satisfação com a vida : um estudo comparativo entre homens e mulheres pertencentes a três grupos de idade. Dissertação de mestrado, Universidade de Campinas, Campinas, SP, Brasil.

Santos, A. T. (2005). Controle percebido: um estudo comparativo entre homens e mulheres. Revista Brasileira de Terapias Cognitivas, 1(1), 91-100.

Sastry, J., \& Ross, C. E. (1998). Asian ethnicity and sense of personal control. Social Psychology Quarterly, 61(2), 101-120.

Schieman, S. (1999). Age and Anger. Journal of Health and Social Behavior, 40(3), 273-289.

Schieman, S. (2001). Age, education, and the sense of control. Research on Aging, 23(2), 153-178.

Schieman, S., Pudrovska, T., \& Milkie, M. A. (2005). The sense of divine control and the selfconcept: a study of race differences in late life. Research on Aging, 27(2), 165-196.

Schieman, S., \& Turner, H. A. (1998). Age, disability, and the sense of mastery. Journal of Health and Social Behavior, 39(3), 169-186. 
Schwenk, C. R. (1984). Cognitive simplification processes in strategic decision-making. Strategic Management Journal, 5(2), 111-128.

Shiller, R. J. (2000). Irrational exuberance. Princeton, NJ: Princenton University Press.

Slovic, P., \& Lichtenstein, S. (1971). Comparison of bayesian and regression approaches in the study of information processing in judgment. Organizational Behavior and Human Performance, 6(6), 649-744.

Teixeira, M. B. (2002). Empoderamento de idosos em grupos direcionados à promoção da saúde. Dissertação de mestrado, Fundação Oswaldo Cruz, Escola Nacional de Saúde Pública, Rio de Janeiro, RJ, Brasil.

Thaler, R., \& Shefrin, H. M. (1981). An economic theory of self-control. Journal of Political Economy, 89(2), 392-406.

Thaler, R. H. (1991). Quasi rational economics. New York: Russel Sage Foundation.

Thaler, R. H.. (1999). The end of behavioral finance. Financial Analysts Journal, 55(6), 12-17.

Thaler, R. H. (2000). From homo economicus to homo sapiens, Journal of Economic Perspectives, 14(1), 133-141.

Turner, R., \& Roszell, P. (1994). Personal resources and stress process. In W. R. Avison \& I. H. Gotlib (Eds.). Stress mental health: contemporary issues and prospects for the future (pp. 179210). New York: Premium.

Tversky, A., \& Kahneman, D. (1971). Belief in the law of numbers. Psychological Bulletin, 76(2), $105-110$.

Tversky, A., \& Kahneman, D. (1974). Judgment under uncertainty: heuristics and biases. Science, 185(4157), 1124-1131.

Wallston, B., \& Wallston, K. A. (1981). Health locus of control scales. In H. M. Lefcourt (Ed.). Research with the locus of control construct (Vol. 1, pp. 189-239). New York: Academic Press.

Zimbarbo, P. G., \& Leippe, M. R. (1991). The psychology of attitude change and social influence. New York: McGraw-Hill. 


\section{APÊNDICE A}

\section{Questionário no}

Data: 2006

Pesquisador:

\section{QUESTIONÁRIO}

Esta pesquisa está desenvolvendo-se sobre a tomada de decisão de investidores. Este questionário consiste em 13 perguntas, e deve levar entre 5 e 7 minutos para ser respondido. Em cada questão, escolha a alternativa que melhor reflete sua própria opinião ou experiência. Suas respostas serão essenciais à conclusão desta pesquisa. Todas as respostas serão mantidas anônimas e serão confidenciais.

\section{Variáveis Demográficas}

1) Sexo:

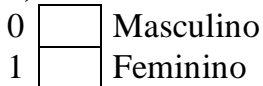

2) Idade:

3) Nível de Instrução

\begin{tabular}{l|l|l}
1 & & Fundamental \\
& & Médio \\
3 & & Superior \\
\cline { 3 - 3 } 4 & & Pós Graduação \\
\cline { 2 - 2 } & & Mestrado/Doutorado
\end{tabular}

Anos de Estudo no total

\section{4) Etnia}

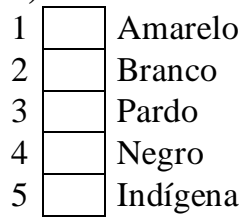

\section{5) Estado civil}

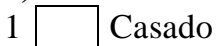

2 Nunca fui casado(a)

3 Divorciado(a)/Separado(a)

\begin{tabular}{|c|c|}
\hline \multicolumn{2}{|c|}{ 6) Situação ocupacional } \\
\hline 1 & Meio expediente \\
\hline 2 & Expediente completo \\
\hline & Estudante \\
\hline & Dona(o) de Casa \\
\hline 5 & Desempregado \\
\hline 6 & Aposentado \\
\hline
\end{tabular}




\section{Outras características pessoais e sociais}

7) Em relação à sua situação financeira atual você está:

Extremamente Satisfeito

$\$$

Eu estou

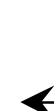

Mais ou menos satisfeito

;
Extremamente Insatisfeito

9

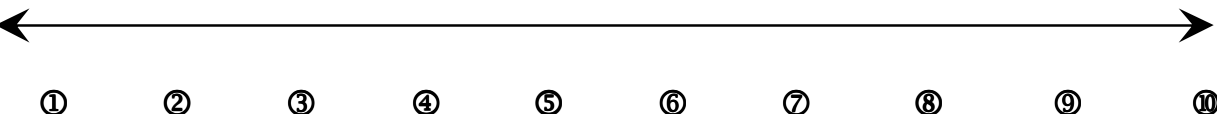

8) Você poderia dizer que sua própria saúde, de um modo geral é:

\section{Fraca}

$\% 2$

(1)
Razoável

(4)
Boa

Excelente

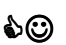

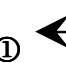

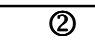

(3)

(5)

(6)

(7)

(8)

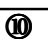

9) Com que freqüência você vai a eventos religiosos como: missas, cultos, encontros e similares?

Várias vezes por semana
$<$

\section{Senso de controle}

10) Eu não tenho muito hábito de planejar as coisas, se algo de bom tem de acontecer acontecerá.

$\begin{array}{lcr}\text { Concordo } & \text { Nem concordo } & \text { Discordo } \\ \text { totalmente } & \text { nem discordo } & \text { totalmente }\end{array}$

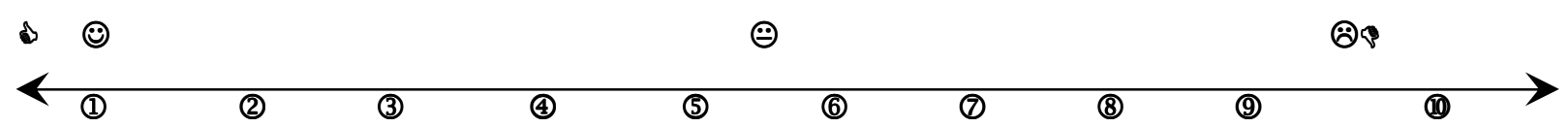

11) A maioria das vezes os meus problemas são devidos a acontecimentos ruins.

\begin{tabular}{|c|c|c|}
\hline Concordo & Nem concordo & Discordo \\
\hline totalmente & nem discordo & totalmente \\
\hline 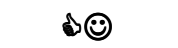 & :) & (2) \\
\hline
\end{tabular}


12) As coisas realmente boas que acontecem comigo são resultado de muita sorte.

\begin{tabular}{|c|c|c|}
\hline Concordo & Nem concordo & Discordo \\
\hline totalmente & nem discordo & totalmente \\
\hline $1 ;$ & :) & (2) \\
\hline
\end{tabular}

13) Eu tenho pouco controle sobre as coisas ruins que acontecem comigo.

\begin{tabular}{|c|c|c|}
\hline Concordo & Nem concordo & Discordo \\
\hline totalmente & nem discordo & totalmente \\
\hline 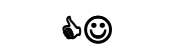 & $\odot$ & 28 \\
\hline
\end{tabular}

Agradecemos sua participação na pesquisa antecipadamente. Caso deseje receber os resultados deste projeto, deixe aqui seu ...

E-mail: $\square$ 


\section{APÊNDICE B}

Estatísticas descritivas da idade dos respondentes (por nível de instrução e sexo)

\begin{tabular}{clcccccc}
\hline Instrução & \multicolumn{1}{c}{ Sexo } & $\mathbf{N}$ & Média & Mediana & DP & Mínimo & Máximo \\
\hline \multirow{2}{*}{ Fundamental } & Masculino & 5 & 50.60 & 55.00 & 12.12 & 30.00 & 60.00 \\
& Feminino & 1 & 29.00 & 29.00 & - & 29.00 & 29.00 \\
\multirow{3}{*}{ Médio } & Masculino & 46 & 27.89 & 24.00 & 12.49 & 16.00 & 76.00 \\
& Feminino & 53 & 30.40 & 24.00 & 14.08 & 15.00 & 77.00 \\
\multirow{3}{*}{ Superior } & Masculino & 123 & 27.91 & 25.00 & 10.41 & 20.00 & 65.00 \\
& Feminino & 134 & 27.63 & 24.00 & 9.93 & 18.00 & 63.00 \\
\multirow{2}{*}{ Mestrado/Doutoradoção } & Masculino & 23 & 41.36 & 40.00 & 12.00 & 27.00 & 74.00 \\
& Feminino & 28 & 36.78 & 34.00 & 9.73 & 23.00 & 63.00 \\
& Masculino & 6 & 40.83 & 48.00 & 12.58 & 21.00 & 51.00 \\
& Feminino & 2 & 34.00 & 34.00 & - & 34.00 & 34.00 \\
\hline \multirow{2}{*}{ Total } & Masculino & 203 & 30.32 & 26.00 & 12.43 & 16.00 & 76.00 \\
& Feminino & 218 & 29.48 & 25.00 & 11.38 & 15.00 & 77.00 \\
\hline
\end{tabular}

